Aim of this study: Chemotherapy-induced peripheral neuropathy (CIPN) is a major complication of cancer patients with chemotherapy. Although many interventions have been evaluated in previous studies, findings are controversial. The aim of this meta-analysis is to assess the efficacy of vitamin E supplementation in preventing CIPN.

Material and methods: The electronic databases MEDLINE, EMBASE, and the Cochrane Central Register of Controlled Trials were systematically searched from their inception to December 31, 2013 to identify relevant randomised controlled trials. Two reviewers independently scanned and extracted the data of included studies. Review Manager 5.2 was used to analyse data.

Results: Six articles involving 353 patients were included in meta-analysis. The results showed that vitamin E supplementation did not appear to significantly decrease the incidence of CIPN (relative risk (RR), 0.55; 95\% confidence interval (Cl), 0.29 to 1.05 ; $p=0.07)$, with significant heterogeneity $\left(1^{2}=77 \%\right)$. However, Vitamin E supplementation can significantly prevent cisplatin associated neurotoxicity $(\mathrm{RR}, 0.31 ; 95 \% \mathrm{Cl}, 0.17$ to 0.58 ; $p=0.0002)$, with no heterogeneity $\left(1^{2}=0 \%\right)$.

Conclusions: Vitamin E administration dose not decrease the incidence of CIPN. However, additional randomised controlled trials using large samples are needed to confirm the role of vitamin E supplementation.

Key words: vitamin E, chemotherapy, neuropathy, prevention, meta-analysis.

Contemp Oncol (Pozn) 20 (3): 237-241 DOI 10.5114/wo.2016.61567

\section{Vitamin E does not decrease the incidence of chemotherapy-induced peripheral neuropathy: a meta-analysis}

Huaping Huang, Mei He, Lihua Liu, Lili Huang

Mianyang Central Hospital, Mianyang, China

\section{Introduction}

Chemotherapy-induced peripheral neuropathy (CIPN) is the most significant, troublesome, and dose-limiting adverse effect of cancer patients who received anticancer agents including cisplatin, oxaliplatin, taxanes, vinca alkaloids, thalidomide, and bortezomib [1, 2]. It has a huge impact on cancer survivors' daily activities and quality of life [3]. CIPN presents as sensory symptoms such as paraesthesia, numbness, pain, and electric-shock-like [4], which may continue or worsen over weeks or months, even after discontinuation of chemotherapy. The prevalence of CIPN ranged from 3\% to $7 \%$ in cancer patients who received single drugs, and increased to $38 \%$ in those treated with multiple chemotherapeutic drugs [5], although this percentage varies depending on chemotherapy regimens, duration of exposure, and assessment methods [6]. In clinical practice settings, CIPN is a major reason for interfering with treatment, resulting in a dose reduction, schedule delay, and cessation of therapy $[7,8]$.

Vitamin $E$ is believed to play a role in protecting neuronal cell bodies against DNA damage and toxic accumulation, and several clinical studies have evaluated the effects of vitamin E during chemotherapy [9-15]. However, the power of the results is limited due to the small sample size. To accumulate evidence and address this issue, we conducted this meta-analysis to evaluate the effectiveness of vitamin $\mathrm{E}$ in preventing CIPN.

\section{Material and methods}

\section{Search strategy}

We followed the Preferred Reporting Items for Systematic Reviews and Meta-Analyses (PRISMA) statement to report this meta-analysis study [16]. The electronic databases MEDLINE, EMBASE, and the Cochrane Central Register of Controlled Trials were systematically searched from their inception to December 31, 2013. The searches were restricted to English publications and human subjects. The reference lists of the original and related reviews were also scanned to identify any potential relevant studies. The following search strategy was used: ((chemotherapy) AND (neurotoxicity OR neuropathy OR peripheral neuropathy OR peripheral neurotoxicity)) AND (vitamin E) AND (randomised controlled trial [pt] OR controlled clinical trial [pt] OR randomised [tiab] OR clinical trials as topic [mesh: no exp] OR randomly [tiab] OR trial [tiab]) NOT (animals [mh] NOT humans [mh]). If the results of the same patients were reported more than once, only the final results were included.

\section{Study selection}

The studies selected and included in the meta-analysis met the following inclusion criteria: 1) study design: randomised controlled trial (RCT); 2) inter- 
vention: oral vitamin E; (3) comparison intervention: placebo or standard care; 3) outcomes reporting: the incidence of neurotoxicity. Studies were excluded if they were nonRCT or were non-human related or were letter, comments, editorials, reviews, and grey literatures.

\section{Data extraction}

To ensure accuracy, two reviewers $(H, H$. P., and $H, M)$ independently scanned and extracted the data of the included studies. Any disagreements were resolved by discussion and consensus. The following information was collected including the first author's name, year of publication, country, study design, sample size, age (years), and definition of intervention.

The primary outcome of interest was the incidence of neurotoxicity (relative risk [RR] with 95\% confidence interval $[\mathrm{Cl}])$. The secondary outcome of interest was the safety of vitamin E administration.

\section{Study quality assessment}

The quality of the included studies was assessed by using the assessment tool described in the Cochrane Handbook for Systematic Reviews of Interventions [17]. All studies were assigned a judgment of low, unclear, or high risk of bias for the following six items: random sequence generation, allocation concealment, blinding (performance bias, detection bias), incomplete outcome data (attrition bias), selective reporting (reporting bias), and other bias. Studies with low risk of bias for all key domains were considered as at low risk of bias. Studies with low or unclear risk for all key domains were considered as at unclear risk

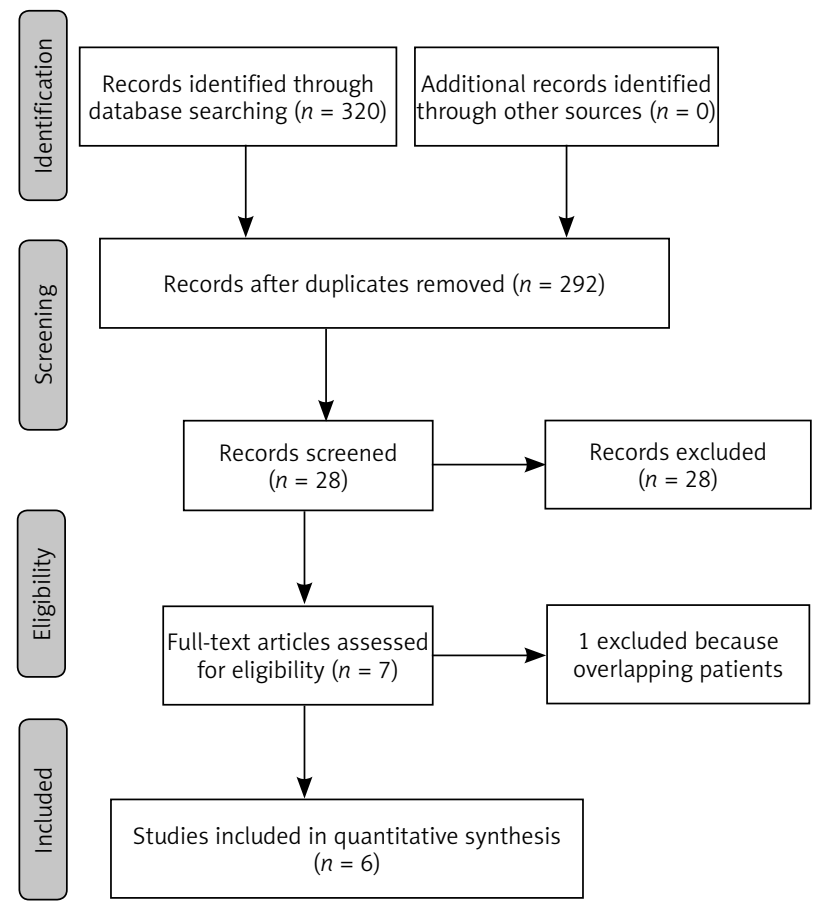

RCT - randomised controlled trial

Fig. 1. Selection process for RCTs included in the meta-analysis of bias. Studies with high risk of bias for any one or more key domains were considered as at high risk of bias [18].

\section{Statistical analysis}

All the data analyses were performed using Review Manager 5.2 (Cochrane Collaboration, Oxford, United Kingdom) following recommendations from the Cochrane handbook. The results from the included studies were pooled to calculate relative risks (RRs) for dichotomous variables with $95 \%$ confidence intervals (Cls). We used Cochrane's Q test and the 12 statistic to assess heterogeneity among combined study results [20]. Heterogeneity between the included trials was indicated when the $p$-value for Cochran's $Q$ test was $<0.1$ and the $R^{2}$ value was $>50 \%$. A random-effects model rather than a fixed-effects model was used as an option for this meta-analysis because the included studies had substantial variations of interventions, populations, and outcomes. Subgroup analyses were conducted based on various exclusion criteria. The small number of the included RCTs did not allow the estimation of potential publication bias with the funnel plot method for the outcomes. All tests were two-sided. $P$-value $<0.05$ was judged as statistically significant.

\section{Results}

The search process is shown in Fig. 1. A total of 320 records were identified in the initial search. After scanning the titles and abstracts, 292 articles were excluded. We reviewed the full-text of 28 studies. Of these remaining studies, 22 studies were excluded with the following reasons: 21 were not RCTs, one article had overlapping patients [10]. Finally, six articles were included in the present meta-analysis study [9, 11-15].

\section{Characteristics of the included studies}

The characteristics of the included studies are presented in Table 1. The sample size ranged from 27 to 189, and 353 patients were involved in the analysis. They were all published after 2003 and in English language. Two studies were conducted in Italy [9, 13], two in Greece [11, 12], one in the USA [14], and one in Brazil [15]. The types of chemotherapeutic formula included platinum-based [9, 12, 13, 15] therapy, paclitaxel-based therapy [11], and various chemotherapeutic agents [14]. The dosage of vitamin E in one study was $300 \mathrm{mg}$ daily [9]; three studies were $300 \mathrm{mg}$ twice daily [11-14], and in one study was $400 \mathrm{mg}$ daily [15].

\section{Outcomes of study quality assessment}

Figure 2 shows the details of assessment for risk of bias tool. Five included studies used a computer to generate random numbers and adequately described the allocation concealment [11-15]. Three of six studies were double-blinded, placebo-controlled studies [13-15]. One of the studies had a high risk of incomplete outcome data bias [9]. In addition, all the studies had a low risk of selective reporting and other biases. Overall, three studies had a high risk of bias $[9,11,12]$ and the others had a low risk of bias [13-15]. 
Table 1. Characteristics of included studies

\begin{tabular}{|c|c|c|c|c|c|c|}
\hline \multirow{2}{*}{$\begin{array}{l}\text { Author } \\
\text { (year, country) }\end{array}$} & \multirow[t]{2}{*}{ Design } & \multirow{2}{*}{$\begin{array}{l}\text { Number of } \\
\text { patients }\end{array}$} & \multicolumn{2}{|c|}{ Age, years } & \multirow[t]{2}{*}{ Interventions } & \multirow[t]{2}{*}{ Incidence of neuropathy } \\
\hline & & & Vitamin $\mathrm{E}$ & Controls & & \\
\hline $\begin{array}{l}\text { Pace et al. } \\
\text { (2003, Italy) [9] }\end{array}$ & $\begin{array}{l}\text { Randomised } \\
\text { clinical study }\end{array}$ & $\begin{array}{l}27 \text { total; vitamin } \\
\text { E: } 13, \text { unblinded } \\
\text { control group: } 14\end{array}$ & $\begin{array}{c}58(37 \text { to } \\
69)\end{array}$ & $\begin{array}{c}57(28 \text { to } \\
74)\end{array}$ & $\begin{array}{l}\text { Vitamin E } 300 \mathrm{mg} / \text { day starting } \\
\text { before cisplatin and continuing } \\
\text { up to } 3 \text { months after cisplatin } \\
\text { treatment }\end{array}$ & $\begin{array}{l}\text { Vitamin E: } 30.7 \% \text {, unblinded } \\
\text { control group: } 85.7 \% ; p<0.01 ; \\
\mathrm{RR}=0.36(95 \% \mathrm{Cl}: 0.15-0.83) \\
p<0.001\end{array}$ \\
\hline $\begin{array}{l}\text { Argyriou et al. } \\
(2006, \text { Greece) } \\
{[11]}\end{array}$ & $\begin{array}{l}\text { Phase II, } \\
\text { randomised } \\
\text { clinical study }\end{array}$ & $\begin{array}{l}32 \text { total; vitamin } \\
\text { E: } 16 \text {, unblinded } \\
\text { control group: } 16\end{array}$ & $56.8 \pm 8.3$ & $\begin{array}{r}57.2 \\
\pm 11.5\end{array}$ & $\begin{array}{l}\text { Vitamin E } 600 \text { mg per day during } \\
\text { chemotherapy and } 3 \text { months after } \\
\text { its cessation }\end{array}$ & $\begin{array}{l}\text { Vitamin E: } 18.7 \% \text {, unblinded } \\
\text { control group: } 62.5 \% ; p=0.03 \\
\mathrm{RR}=0.3(95 \% \mathrm{Cl}: 0.1-0.9)\end{array}$ \\
\hline $\begin{array}{l}\text { Argyriou et al. } \\
(2006, \text { Greece) } \\
{[12]}\end{array}$ & $\begin{array}{l}\text { Phase, } \\
\text { randomised } \\
\text { clinical study }\end{array}$ & $\begin{array}{l}30 \text { total; vitamin } \\
\text { E: } 14 \text {, unblinded } \\
\text { control group: } 16\end{array}$ & $\begin{array}{r}53.6 \\
\pm 14.8\end{array}$ & $\begin{array}{r}59.3 \\
\pm 12.8\end{array}$ & $\begin{array}{l}\text { Vitamin E } 600 \mathrm{mg} / \text { day or placebo } \\
\text { during and for } 3 \text { months after } \\
\text { completion of chemotherapy } \\
\text { treatment. }\end{array}$ & $\begin{array}{l}\text { Vitamin E: } 21.4 \% \text {, unblinded } \\
\text { control group: } 68.5 \% ; p=0.026 ; \\
R R=0.31(95 \% \mathrm{Cl}: 0.11-0.9)\end{array}$ \\
\hline $\begin{array}{l}\text { Pace et al. } \\
\text { (2010, Italy) } \\
{[13]}\end{array}$ & $\begin{array}{l}\text { Randomised, } \\
\text { controlled } \\
\text { study }\end{array}$ & $\begin{array}{l}41 \text { total; vitamin } \mathrm{E}: \\
\text { 17, placebo: } 24\end{array}$ & $\begin{array}{c}58 \\
(28-71)\end{array}$ & $\begin{array}{c}58.5 \\
(32-74)\end{array}$ & $\begin{array}{l}\text { Vitamin E } 400 \text { mg per day before } \\
\text { chemotherapy and lasted for } \\
3 \text { months after cisplatin therapy }\end{array}$ & $\begin{array}{l}\text { Vitamin E: } 5.9 \% \text {, Placebo: } 41.7 \% \text {; } \\
p<0.01 ; \mathrm{RR}=0.14(95 \% \mathrm{Cl}, 0.02 \\
-1.00)\end{array}$ \\
\hline $\begin{array}{l}\text { Kottschade } \\
\text { et al. } \\
\text { (2011, USA) [14] }\end{array}$ & $\begin{array}{l}\text { phase III, } \\
\text { randomised, } \\
\text { controlled } \\
\text { study }\end{array}$ & $\begin{array}{l}189 \text { total; vitamin } \\
\text { E: } 96, \text { placebo: } 93\end{array}$ & NR & NR & $\begin{array}{l}\text { Vitamin E } 300 \text { mg, twice daily, } \\
\text { initiated within } 4 \text { days before } \\
\text { chemotherapy and continued } \\
1 \text { month after chemotherapy. }\end{array}$ & $\begin{array}{l}\text { Vitamin E: } 34 \%(95 \% \mathrm{Cl}, 25.0 \% \\
\text { to } 44.8 \%) \text {, Placebo: } 29 \%(95 \% \mathrm{Cl} \text {, } \\
20.1 \%-39.4 \%) ; p=0.43 .\end{array}$ \\
\hline $\begin{array}{l}\text { Afonseca et al. } \\
(2013, \text { Brazil) } \\
{[15]}\end{array}$ & $\begin{array}{l}\text { Phase II, } \\
\text { randomised, } \\
\text { controlled } \\
\text { study }\end{array}$ & $\begin{array}{l}34 \text { total; vitamin } \mathrm{E}: \\
\text { 18, placebo:16 }\end{array}$ & $\begin{array}{c}56 \\
(29-76)\end{array}$ & $\begin{array}{c}57 \\
(40-71)\end{array}$ & $\begin{array}{l}\text { Vitamin E } 400 \mathrm{mg} / \text { day, five } \\
\text { days before starting oxaliplatin } \\
\text { treatment until the end of the } \\
\text { chemotherapy. }\end{array}$ & $\begin{array}{l}\text { Vitamin E: } 83 \% \text {, Placebo: } 68 \% \text {; } \\
p=0.45 .\end{array}$ \\
\hline
\end{tabular}

Age was reported as median (range) or mean $\pm S D$

$R R$ - relative risk; $\mathrm{Cl}$-confidence interval; $N R$ - not reported

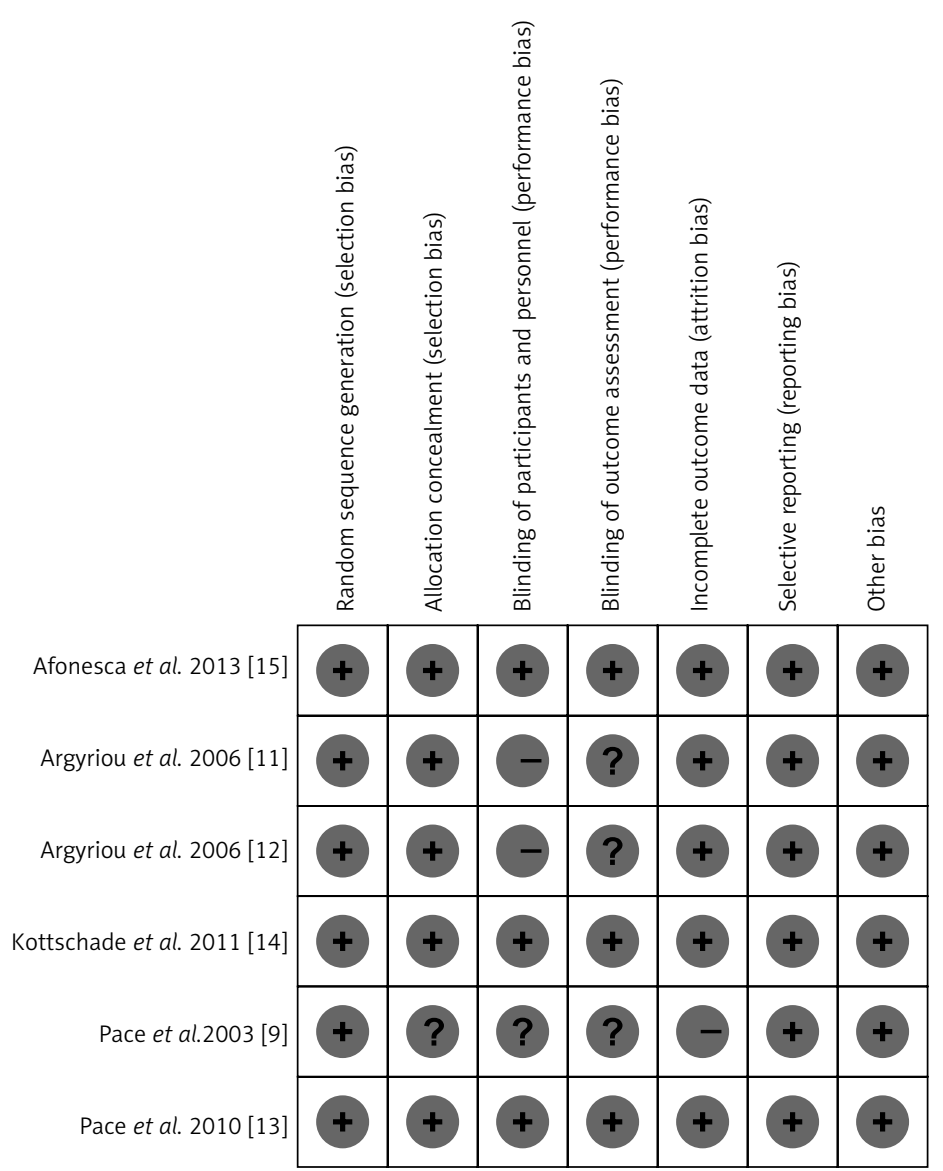

Fig. 2. Summary for risk of bias assessment 
Table 2. Subgroup analyses for vitamin E in preventing chemotherapy-induced peripheral neuropathy

\begin{tabular}{|c|c|c|c|c|c|c|c|}
\hline Outcome & $\begin{array}{l}\text { No. of } \\
\text { patients }\end{array}$ & $\begin{array}{l}\text { No. of } \\
\text { studies }\end{array}$ & Vitamin E & $\begin{array}{l}\text { Control } \\
\text { subjects }\end{array}$ & $\operatorname{RR}(95 \% \mathrm{CI})$ & $p$-value & $I^{2}(\%)$ \\
\hline All included studies & 353 & 6 & 59 of 174 & 81 of 179 & $0.55(0.29-1.05)$ & 0.07 & 77 \\
\hline High-quality trials (low risk of bias) & 264 & 3 & 49 of 131 & 48 of 133 & $1.03(0.59-1.80)$ & 0.92 & 62 \\
\hline Vitamin E vs. placebo & 264 & 3 & 49 of 131 & 48 of 133 & $1.03(0.59-1.80)$ & 0.92 & 62 \\
\hline Multicentre study & 230 & 2 & 34 of 113 & 37 of 117 & $0.50(0.06-4.27)$ & 0.53 & 79 \\
\hline Cisplatin-based formula & 98 & 3 & 8 of 44 & 33 of 54 & $0.31(0.17-0.58)$ & 0.0002 & 0 \\
\hline
\end{tabular}

$R R$ - relative risk; $\mathrm{Cl}$ - confidence interval

\section{The effects of vitamin E on incidence of CIPN}

All six studies [9, 11-15] were used to calculate the pooled incidence of CIPN in patients between two groups. Overall, the incidence of neurotoxicity in the vitamin E group was lower than in the placebo group ( $R R=0.55$ 95\% Cl: 0.29-1.05; $p=0.07$; Fig. 3), and with significant heterogeneity $\left(I^{2}=77 \%\right)$. Table 2 shows the results of subgroup analysis based on various outcomes. Only one pooled result showed that vitamin E administration could significantly decrease the incidence of cisplatin-related neurotoxicity ( $R R=0.31 ; 95 \% \mathrm{Cl}: 0.17-0.58 ; p=0.0002)$, with low heterogeneity $\left(R^{2}=0 \%\right)$.

\section{The safety of oral vitamin E}

Four of the six included studies assessed the safety of vitamin E during chemotherapy [11, 12, 14, 15], and no adverse events were observed.

\section{Discussion}

CIPN is a significant adverse effect for cancer patients with chemotherapy; however, there are currently no confirmed effective preventative interventions available for clinical practice in patients with this complication. While many pharmacological agents such as glutathione [21], calcium and magnesium infusion [22], and venlafaxine [23] have been studied, CIPN continues to be a challenge in treating these patients.
The results from our meta-analysis provide some evidence that vitamin E supplementation does not decrease the incidence of neuropathy in cancer patients who are undergoing chemotherapy. In contrast, we found in subgroup analysis that vitamin E can significantly decrease the incidence of cisplatin-related neuropathy, which is in line with a previous systematic review [24]. A potential reason is the inclusion of many different types of chemotherapy in primary outcome analysis, which results in different mechanisms of action to induce neuropathy.

Additionally, the safety of vitamin E supplementation has also been tested in this meta-analysis. Patients in this study were given a high dose of vitamin $E$ that varied from $300 \mathrm{mg}$ to $600 \mathrm{mg}$ per day, and no adverse effects and intolerance related to vitamin $\mathrm{E}$ administration were recorded. Meanwhile, one clinical study approved that vitamin $\mathrm{E}$ supplementation does not disturb the antitumor activities of chemotherapeutic agents [9]. However, the reasonable upper intake dosage of vitamin $\mathrm{E}$ is still controversial. One systematic review [25] suggested that high-dosage (> 400 IU/d) vitamin E supplements may increase all-cause mortality. In contrast, a recent meta-analysis [26] involving 246,371 subjects showed no relationship between dose and risk of mortality. Therefore, more well-designed clinical trials regarding the reasonable dosage and periods of vitamin E supplementation are needed.

The present meta-analysis also has several limitations that must be considered. Firstly, the small sample size of

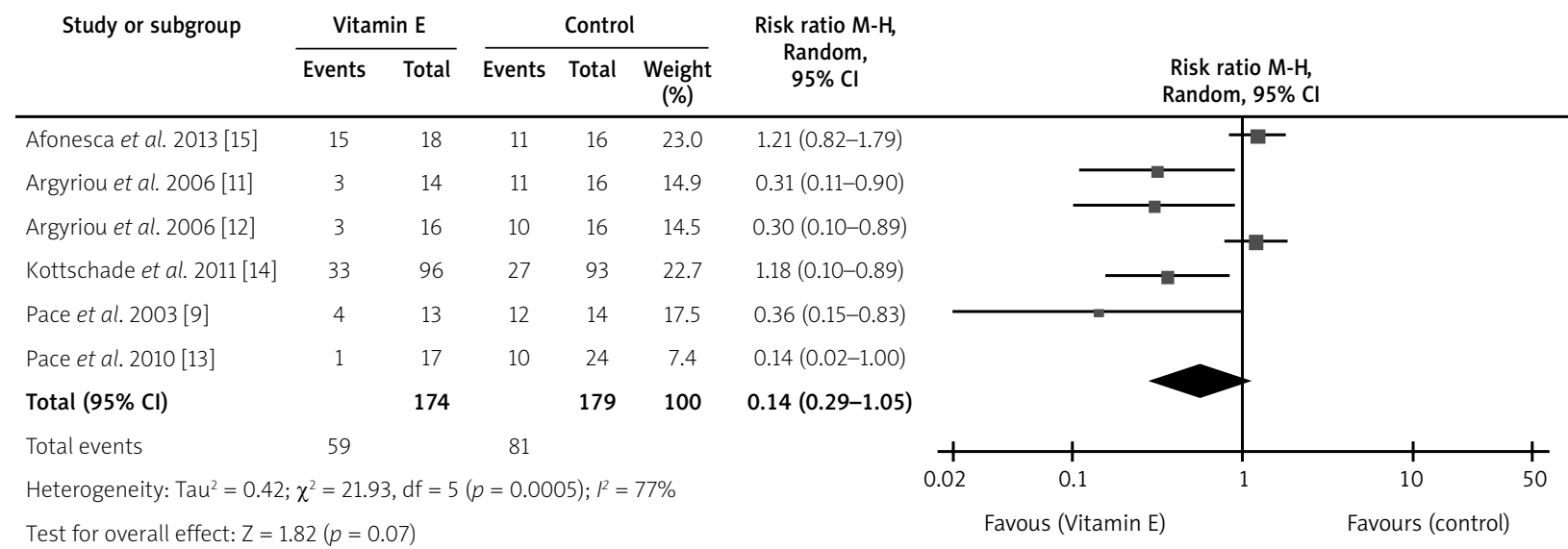

Fig. 3. Meta-analysis of RCTs evaluating effects of vitamin E on incidence of CIPN. There was no significant effect on incidence of CIPN as determined by the random-effects model 
these studies makes this study less than convincing. Secondly, half of the included studies did not use the double-blinded method, which could result in performance bias. Thirdly, the included studies did not adequately evaluate long-term quality of life after using vitamin E, which is an important outcome for patients with cancer.

Chemotherapy-induced peripheral neuropathy is a troublesome complication of cancer patients receiving chemotherapeutic drugs. This meta-analysis show that vitamin E dose not significantly decrease the incidence of CINP. However, more high-quality studies with large sample size are needed to confirm these findings.

This study was supported by a grant from Mianyang Central Hospital (Funding number: 2014YJ28). The authors declare no conflicts of interest.

\section{References}

1. Park SB, Goldstein D, Krishnan AV, et al. Chemotherapy-induced peripheral neurotoxicity: A critical analysis. CA Cancer J Clin 2013; 63: 419-37.

2. Burton AW, Fanciullo GJ, Beasley RD, et al. Chronic pain in the cancer survivor: a new frontier. Pain Med 2007; 8: 189-98.

3. Driessen CM, de Kleine-Bolt KM, Vingerhoets AJ, et al. Assessing the impact of chemotherapy-induced peripheral neurotoxicity on the quality of life of cancer patients: the introduction of a new measure. Support Care Cancer 2012; 20: 877-81.

4. Han Y, Smith MT. Pathobiology of cancer chemotherapy-induced peripheral neuropathy. Front Pharmacol 2013; 18: 156-72.

5. Kautio AL, Haanpää M, Kautiainen H, et al. Burden of chemotherapy-induced neuropathy - a cross-sectional study. Support Care Cancer 2011; 19: 1991-7.

6. Cavaletti G, Cornblath DR, Merkies IS, et al. The chemotherapy-induced peripheral neuropathy outcome measures standardization study: from consensus to the first validity and reliability findings. Ann Oncol 2013; 24: 454-62.

7. Visovsky C, Collins M, Abbott L, et al. Putting evidence into prac tice: evidence-based interventions for chemotherapy-induced peripheral neuropathy. Clin J Oncol Nurs 2007; 11: 901-13.

8. Bhatnagar B, Gilmore S, Goloubeva O, et al. Chemotherapy dose reduction due to chemotherapy induced peripheral neuropathy in breast cancer patients receiving chemotherapy in the neoadjuvant or adjuvant settings: a single-center experience. Springerplus 2014; 3: 366

9. Pace A, Savarese A, Picardo M, et al. Neuroprotective effect of vitamin E supplementation in patients treated with cisplatin chemotherapy. J Clin Oncol 2003; 21: 927-31.

10. Argyriou AA, Chroni E, Koutras A, et al. Vitamin E for prophylaxis against chemotherapy-induced neuropathy: a randomized controlled trial. Neurology 2005; 64: 26-31.

11. Argyriou AA, Chroni E, Koutras A, et al. Preventing paclitaxel-induced peripheral neuropathy: a phase II trial of vitamin E supplementation. J Pain and Symptom Manage 2006; 32: 237-44.

12. Argyriou AA, Chroni E, Koutras A, et al. A randomized controlled trial evaluating the efficacy and safety of vitamin E supplementation for protection against cisplatin-induced peripheral neuropathy: final results. Support Care Cancer 2006; 14: 1134-40.

13. Pace A, Giannarelli D, Galiè E, et al. Vitamin E neuroprotection for cisplatin neuropathy: a randomized, placebo-controlled trial. Neurology 2010; 74: 762-6.

14. Kottschade LA, Sloan JA, Mazurczak MA, et al. The use of vitamin $E$ for the prevention of chemotherapy-induced peripheral neuropathy: results of a randomized phase III clinical trial. Support Care Cancer 2011; 19: 1769-77.
15. Afonseca SO, Cruz FM, Cubero Dde I, et al. Vitamin E for prevention of oxaliplatin-induced peripheral neuropathy: a pilot randomized clinical trial. Sao Paulo Med J 2013; 131: 35-8.

16. Moher D, Liberati A, Tetzlaff J, et al. Preferred reporting items for systematic reviews and meta-analyses: the PRISMA statement. Ann Intern Med 2009; 151: 264-9.

17. Higgins JPT, Green S. Cochrane Handbook for Systematic Reviews of Interventions version 5.1.0 (updated March 2011) (http://handbook.cochrane.org/). Last accessed 25 May 2014.

18. Higgins JP, Altman DG, Gøtzsche PC, et al. The Cochrane Collaboration's tool for assessing risk of bias in randomized trials. BMJ 2011, 343: d5928.

19. Guyatt GH, Oxman AD, Vist GE, et al. GRADE: an emerging consensus on rating quality of evidence and strength of recommendation. BMJ 2008; 336: 924-6.

20. Higgins JP, Thompson SG, Deeks JJ, et al. Measuring inconsistency in meta-analyses. BMJ 2003; 327: 557-60.

21. Cascinu S, Catalano V, Cordella L, et al. Neuroprotective effect of reduced glutathione on oxaliplatin-based chemotherapy in advanced colorectal cancer: a randomized, double-blind, placebocontrolled trial. J Clin Oncol 2002; 20: 3478-83.

22. Knijn N, Tol J, Koopman M, et al. The effect of prophylactic calcium and magnesium infusions on the incidence of neurotoxicity and clinical outcome of oxaliplatin-based systemic treatment in advanced colorectal cancer patients. Eur J Cancer 2011; 47: 369-74.

23. Durand JP, Deplanque G, Montheil V, et al. Efficacy of venlafaxine for the prevention and relief of oxaliplatin-induced acute neurotoxicity. Ann Oncol 2012; 23: 200-5.

24. Albers JW, Chaudhry V, Cavaletti G, et al. Interventions for preventing neuropathy caused by cisplatin and related compounds. Cochrane Database Syst Rev 2011; 16: CD005228.

25. Miller ER, Pastor-Barriuso R, Dalal D, et al. Meta-analysis: high-dosage vitamin E supplementation may increase all-cause mortality. Ann Intern Med 2005; 142: 37-46.

26. Abner EL, Schmitt FA, Mendiondo MS, et al. Vitamin E and allcause mortality: a meta-analysis. Curr Aging Sci 2011; 4: 158-70.

\section{Address for correspondence}

Huaping Huang

Mianyang Central Hospital

No.12 Changjia Alley

Jingzhong Street,Fucheng District

621000 Mianyang, China

e-mail: jrzhou26@aliyun.com

Submitted: 2.09.2014

Accepted: 19.11.2014 